\title{
Effect of the Pigment Concentration on the Dimensional Stability and the Melt Flow Index of Polycarbonate
}

Vaclav Janostik, Michal Stanek, Vojtech Senkerik, Petr Fluxa, Lenka Hylova

Faculty of Technology, Tomas Bata University in Zlin. Vavreckova 275, 76001 Zlin. Czech Republic. E-mail: vjanostik@utb.cz,

This study is focused on the effect of pigments on polycarbonate (PC), especially the dimensional stability and flow properties of this material. This polymer is commonly used in the plastics industry and the most common processing of this polymer is injection molding technology. Three different pigments made by Lifocolor company were selected for PC staining. In addition, six different concentrations of aforementioned pigments were used. It is worthwhile to note that the pigments in the polymer matrix acted as a filler. Just like fillers, the pigments also influence the shrinkage of the polymer in both the main and secondary directions. The paper also deals with the effect of pigment concentration on the melt index (MFI). It was shown that the presence of pigments reduces the thermal mobility of the macromolecular chain. Melt flow index changes were also directly tied to the changes of the viscosity, which was also affected by the pigments. It can be expected that the viscosity might not remain the same even at varying shear rates.

Keywords: Injection moulding, shrinkage, dimensional stability, pigment concentration, melt flow index

\section{Introduction}

Nowadays, polymers are irreplaceable in the industry, because of their material properties and easy processing. [1] For the improvement of the production efficiency, a lot of moulded parts are created using the injection moulding technology. [1]

There are three basic colouring methods. [2] Dry dyeing is commonly used for the injection moulding technology. [1] This type of colouring is composed of direct mixing of a basic polymeric material coloured in the individual concentration of the pigments. [2] To obtain the greater pigment distribution in the basic polymer, mass or volume dosing of the pigments is applied.

It is difficult to obtain desired colour shade. Each shade requires different pigment concentration. [3] The pigments do not influence the mechanical properties significantly. [6] However, they have a certain influence on rheological properties such as melt flow index, shrinkage and flow-curve. [2] All these parameters are to be considered during finding the appropriate colour shade.

In this study, the shrinkage and the dimensional stability of the polymeric material coloured by using the pigments, are measured. [9] Results show, that he shrinkage is influenced by the pigments. [5] The emphasis was also placed on the melt flow index measurement. This property was influenced by pigments as well.

\section{Methods}

\section{Type of polymeric material and pigment}

PC Lexan 923A from company SABIC was selected as the basic polymeric material. This polymer is commonly used in the plastics industry and mostly processed by injection moulding. PC is an amorphous thermoplastic material having a high impact resistance. The blends were prepared using this polymer with three various pigments, which were obtained from the company LIFOCOLOR. The shades of these obtained pigments were red (3620 F/PC), blue (4842 F/PC) and green (50009 F/PC) and are also compatible for coloring of PC.

\section{Formation of the mixture}

Dry blending was used for the preparation of the blend. Stirring was strictly carried out in the exact dose of Lexan

923A polymer granulate with individual pigments. Blending used commonly in the plastics industry was used. The blends were prepared in concentration (1-6\%).

Tab. 1 Formation of the mixture

\begin{tabular}{|c|r|r|r|r|}
\hline $\mathbf{C}_{\text {pigment }}$ & $\mathbf{C}_{\text {polymer }}$ & $\mathbf{m}_{\text {pigment }}$ & $\mathbf{m}_{\text {polymer }}$ & \multicolumn{1}{l|}{$\mathbf{M}_{\text {mix }}$} \\
\hline $1 \%$ & $99 \%$ & $15 \mathrm{~g}$ & $1485 \mathrm{~g}$ & $1500 \mathrm{~g}$ \\
\hline $2 \%$ & $98 \%$ & $30 \mathrm{~g}$ & $1470 \mathrm{~g}$ & $1500 \mathrm{~g}$ \\
\hline $3 \%$ & $97 \%$ & $45 \mathrm{~g}$ & $1455 \mathrm{~g}$ & $1500 \mathrm{~g}$ \\
\hline $4 \%$ & $96 \%$ & $60 \mathrm{~g}$ & $1440 \mathrm{~g}$ & $1500 \mathrm{~g}$ \\
\hline $5 \%$ & $95 \%$ & $75 \mathrm{~g}$ & $1425 \mathrm{~g}$ & $1500 \mathrm{~g}$ \\
\hline $6 \%$ & $94 \%$ & $90 \mathrm{~g}$ & $1410 \mathrm{~g}$ & $1500 \mathrm{~g}$ \\
\hline
\end{tabular}

\section{Production of test specimens}

Tested samples were prepared using the injection moulding machine ARBURG Allrounder 470H 1000-400 Injector.

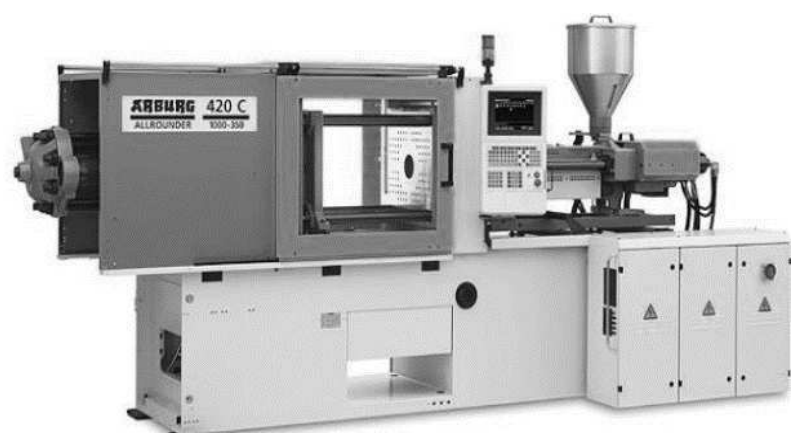

Fig. 1 Injection machine 
Tab. 2 Injection Parameters

\begin{tabular}{lcc}
\hline Melt temperature & 300 & ${ }^{\circ} \mathrm{C}$ \\
Mould temperature & 100 & ${ }^{\circ} \mathrm{C}$ \\
Injection speed & 40 & $\mathrm{~mm} / \mathrm{s}$ \\
Filing time & 1.2 & $\mathrm{~S}$ \\
Packing pressure & 30 & $\mathrm{MPa}$ \\
Injection pressure & $\mathbf{8 0 0}$ & $\mathrm{Bar}$ \\
Cool time & 30 & $\mathrm{~S}$ \\
Time packing pressure & 15.5 & $\mathrm{~s}$ \\
Cycle time & 40 & $\mathrm{~s}$ \\
Weight & 25.7 & $\mathrm{~g}$
\end{tabular}

\section{Shrinkage of the polymer}

Injected thermoplastics differ by dimensions between the mould cavity and the dimensions of the finished product. The changes in dimensions also affect mould design and process injection conditions. These differences depend on the injection moulding capacity, the shape and size of the injection, the direction of flow during filling of the cavity and, above all, the choice of technological parameters of the injection process. The production and additional shrinkage is caused by the material crystallization, relaxation of the material, orientation and thermal contraction of both the thermoplastic and the injection mould. The measurement of the production and the additional shrinkage is appropriate for comparison of different thermoplastics and for the control of the uniformity of the production. The data obtained by this method are useful for the determination of the material suitability for the production of precisely sized injection moulded products.

\section{Shrinkage Measurement}

Shrinkage measurements can be divided into production shrinkage measurements, which is measured almost immediately after the test sample is injected and additional shrinkage measurements. The time between measuring of the production and subsequent shrinkage must be defined by the relevant material standard or agreed between the involved parties. In the end, the overall shrinkage (production and additional shrinkage) was measured 48 hours after test sample production.

The measurement of the shrinkage is performed by means of a gauge capable of measuring the length and width of the test body and the shape of the mould cavity with an accuracy of $0.02 \mathrm{~mm}$. The test sample can be measured between the centers of the opposite sides or between the two reference marks. Shrinkage is measured in the main direction (in the direction of the flow) and in a side direction perpendicular to the direction of the flow.

$$
\begin{gathered}
S_{p 1}=100 \frac{l_{1}-l_{2}}{l_{1}} \\
S_{p 2}=100 \cdot \frac{b_{1}-b_{2}}{b_{1}}
\end{gathered}
$$

Where:

$\mathrm{S}_{\mathrm{p} 1 \ldots}$.. Main shrinkage [\%],

$\mathrm{S}_{\mathrm{p} 2 \ldots}$ Secondary shrinkage [\%],

$1_{1} \ldots$ length of the cavities [mm],

$1_{2} \ldots$ length of the sample $[\mathrm{mm}]$,

$\mathrm{b}_{1} \ldots$ width of the cavities [mm],

$\mathrm{b}_{2} \ldots$ width of the sample $[\mathrm{mm}]$,

\section{Test bodies}

The shrinkage of the test bodies was measured four days after the injection moulding. The ISO 294-4 standard was followed doring this measurement. The test bodies were in the shape of the prism with the dimension of $80 \times 10 \times 4 \mathrm{~mm}$. The shrinkage was measured in the main direction (direction of the flow) and in the side direction. Ten test pieces were used for each set of measurements. The test bodies were conditioned and measured in a test room at $20^{\circ} \mathrm{C}$.

\section{Checking dimensional stability}

The Zeiss Conture gauge was used to measure the dimensional stability. This device uses the ceramic guides to ensure the stiffness and low thermal expansion. The air bearings in all three axes ensure constant stability even at high speeds and acceleration. Additionaly, the device has a glass ceramic scale that is almost non-extensible and does not require temperature numbers. This device is capable of measuring accurately to $0.0001 \mathrm{~mm}$ guaranteeing the high quality and reliability of the measured results.

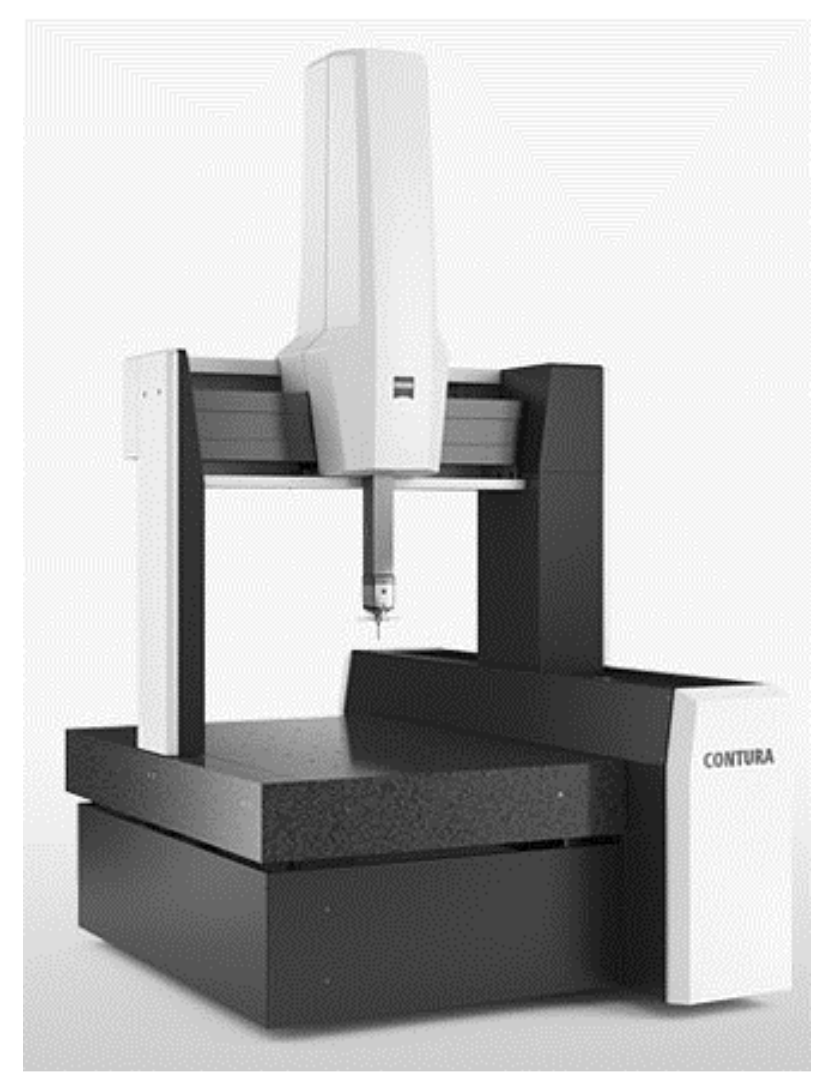

Fig. 2 Contour measuring device

\section{Melt flow index}

The melt flow index (MFI) is a measure of the ease of flow of melted plastics. It is defined as the mass of polymer in grams, flowing through a capillary of a specific diameter and length by a pressure applied via prescribed alternative gravimetric weights for alternative prescribed temperatures in ten minutes. MFI measurement is an indirect way to measure the molecular weight. For example, high MFI corresponds with low molecular weight. At the 
same time, MFI is a measurement of the ability of the polymer melt to flow under pressure. For our case, method A defined by ISO 1133 was selected.

\section{Preparation of the test mixture}

In order to obtain the homogenity of the pigment in the mixture, the first fraction of the recyclation of the test samples was used. The test samples were first produced by the injection moulding method on which the dimensional stability was measured; these bodies were then crushed and used for MFI measurements.

\section{Results}

\section{Shrinkage in the direction of the flow}

Fig. 3 depicts the shrinkage of polymeric materials in the main direction. As can be seen on the graph, the shrinkage slightly decreases with increasing pigment concentration. In the concentration range from $2 \%$ to $4 \%$, there is a slight stabilization. These concentrations are considered as optimal. The largest shrinkage was achieved with a mixture of the red pigment. This shrinkage is $5 \%$ relative to the shrinkage of the base polymer.

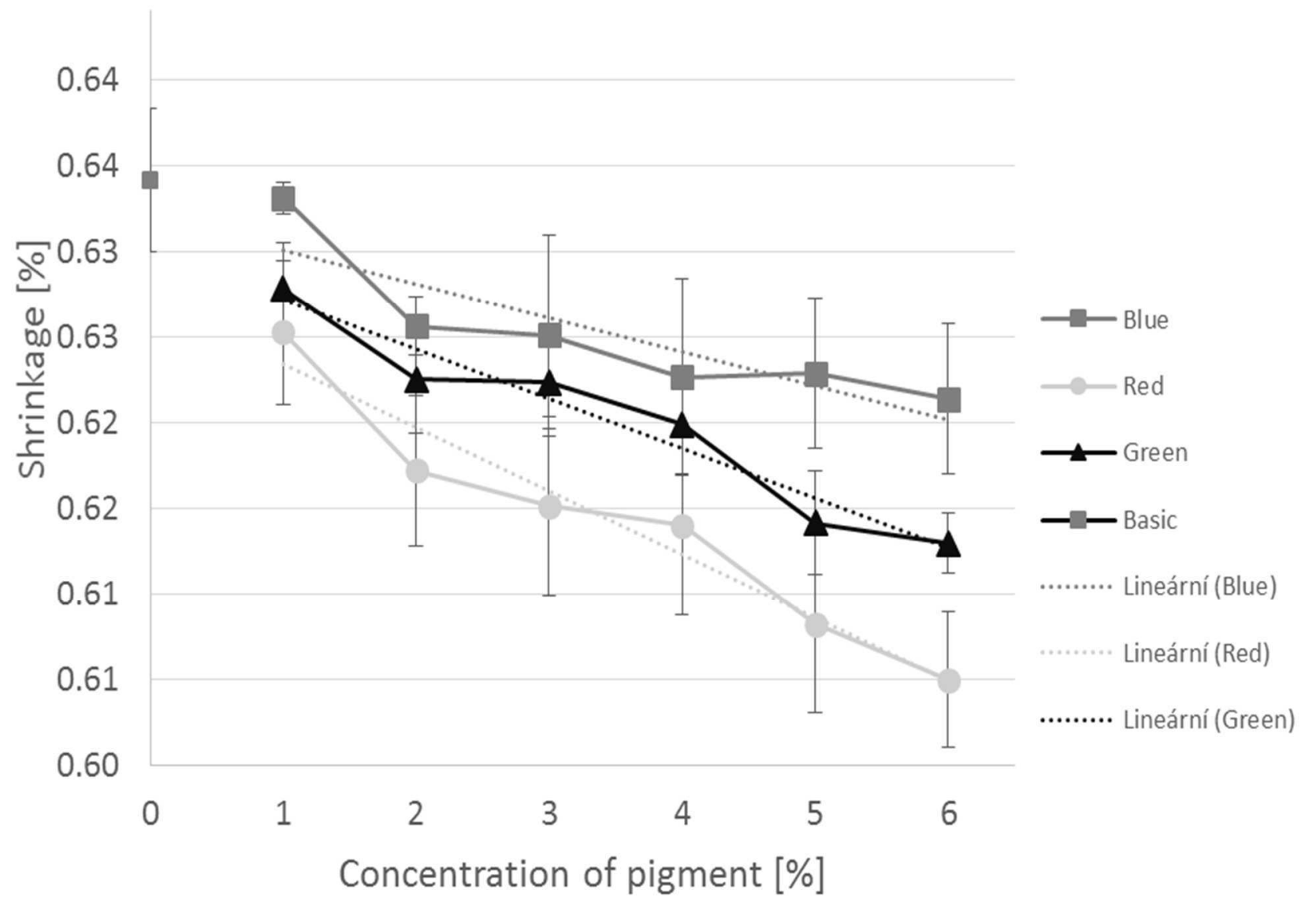

Fig. 3 Shrinkage (main direction) vs. concentration of the pigment

\section{Shrinkage in the side direction}

Fig. 4 shows the shrinkage of polymeric materials in the side direction. In contrast to the shrinkage in the main direction, there is a different behaviour. This behaviour is perceived as an increase. It is caused by the pseudoplastic behavior of polymeric materials. Due to the relaxation of the macromolecules, there is a slight return to the original condition. The largest shrinkage occurred again with the use of a red pigment. It is $2 \%$ relative to the base polymer.

Moreover, as can be seen on the figure, the side shrinkage displays a smaller variance of the measured values of the blue pigment, a smaller standard deviation, and thus the resulting mixtures behave more constantly. Red color pigment mixtures have a much higher standard deviation.

Amorphous polymer shrinkage can be explained by the pseudoplastic behaviour of the melt and its tendency to return to the stable state. Fountain flow (Fig. 5), which is a combination of shear and elongation flow, is a common phenomenon during the injection moulding process. The macromolecular chains of the polymer melt are extended as a result of the prevailing elongation flow. This leads to the creation of the disordered structure and these macromolecules generate entanglements. Fountain flow has the crucial impact on the macromolecular chain orientation and the creation of the anisotropic structure. The existence of the anisotropic structure explains the difference between the shrinkage in the main flow direction and the side flow direction.

Frozen tensions and material relaxation also contribute to the differences in the shrinkage of the amorphous thermoplastics. The shrinkage in main flow direction is reduced while the shrinkage in the side flow direction is enchanced. At this moment, the final volume remains the same. 


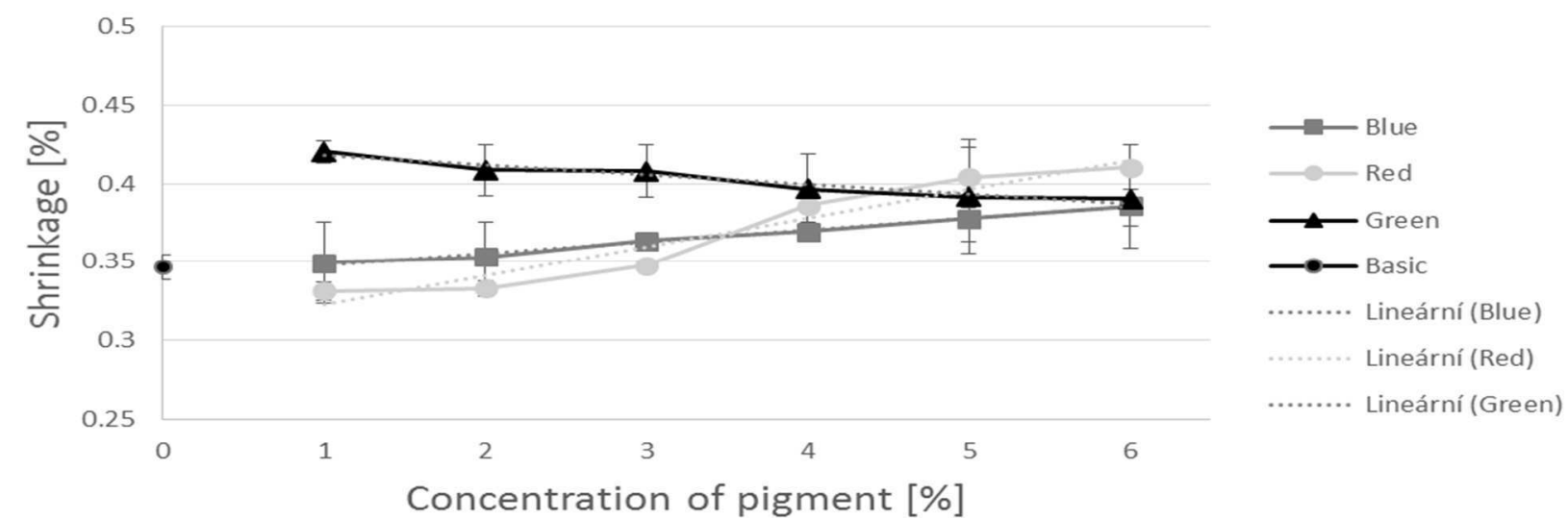

Fig. 4 Shrinkage (side direction) vs. concentration of the pigment

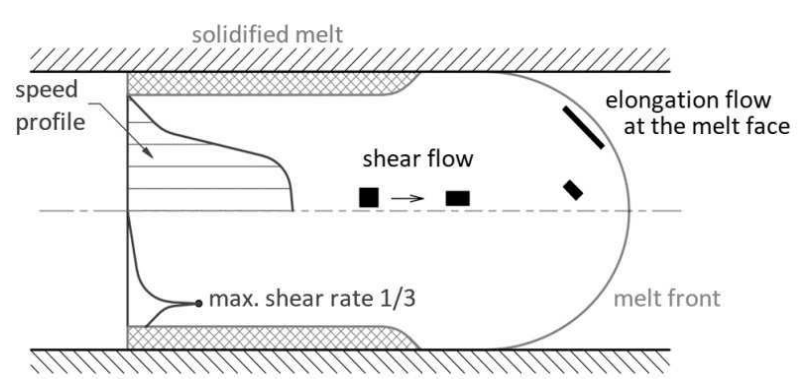

Fig. 5 Fountain flow

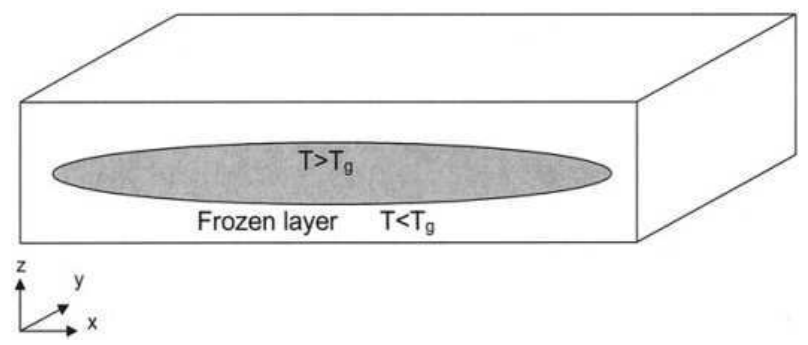

Fig. 6 Effect of frozen tension and melt recovery

The closing pressure and the pressure in the mould cavity declines as the polymer melt flow stops at the end of the packing phase during the injection mould process. At this moment, the elastic relaxation of the part core is possible $(\mathrm{T}>\mathrm{Tg}$ ). These frozen tensions and elastic relexations (Fig. 6) result in the differences between the main flow direction and the side flow direction.

The different pigments also contribute to the dshrinkage differences. The influence of the pigments on the final part depends on the particle surface, the amount in the colour concentrate and the pigment composition. The presence of the pigments may lead to the minor stiffening effect similarly to the function of the fillers. In this case, the pigments influence the base polymer in the same manner as fillers. In addition, they reduce the shrinkage of the final polymer part.

\section{Melt flow index}

The effect of the pigment concentration on the polymer melt flow index is shown in the Fig. 7. As shown in the graph, there is a decrease in MFI when using the red pigment. Subsequently, MFI moderately grows with increasing pigment concentrations. Similarly, there is a steady increase in MFI for the blue pigment. However, when using a green pigment, the trend is inverse. There is a slight decrease and with increasing pigment concentration.

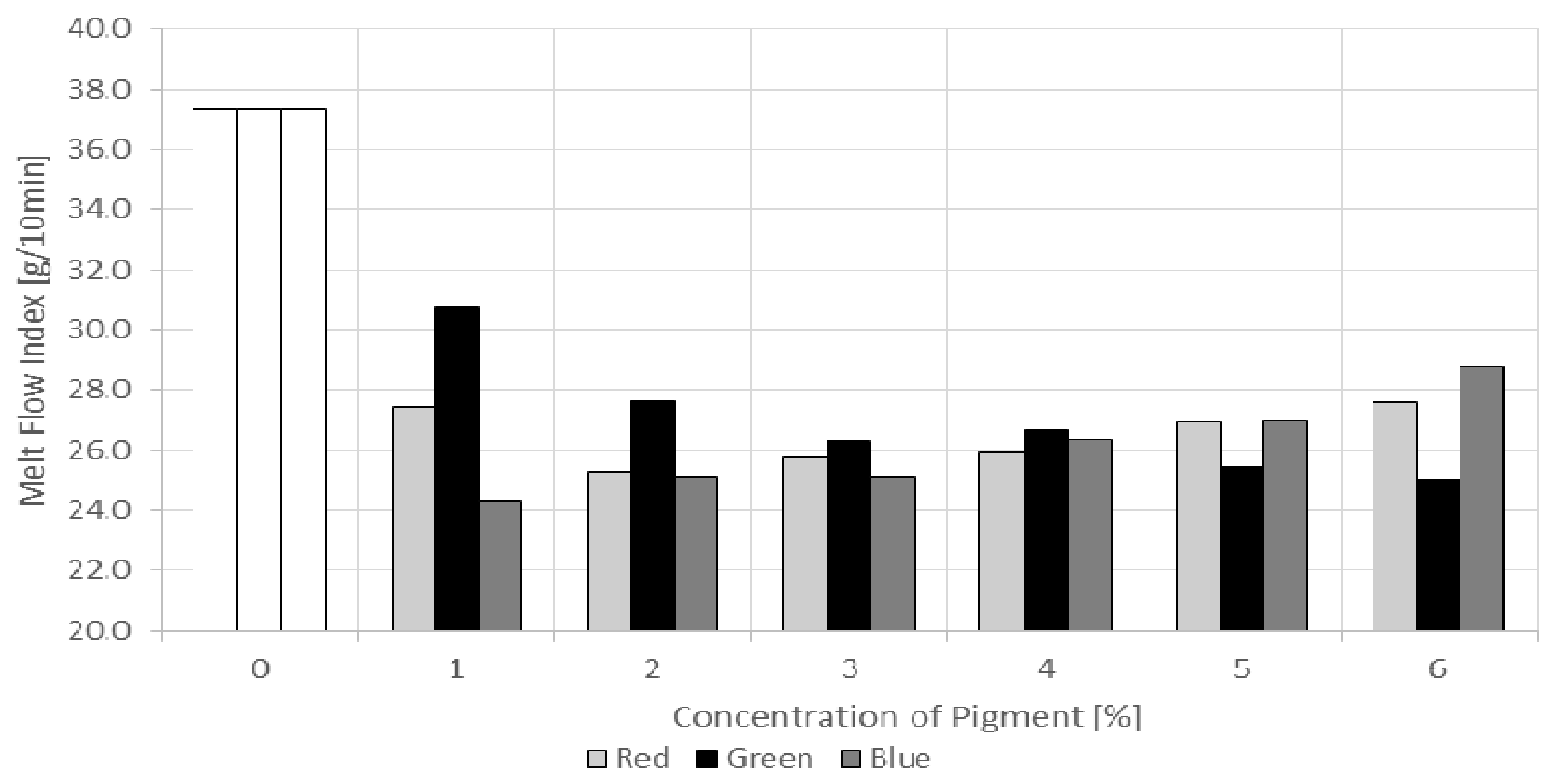

Fig. 7 Melt flow index vs. concentration of the pigment 
As can be seen, MFI decreased by about 30\% for all tested pigments independently of its concentration. On the other words, the polymer melt flow ability was reduced. This change can cause complications in processing of this polycarbonate using injection molding technology, for example the melt does not flow into all locations of a mold cavity.

From the physical point of view it is evident, that the pigments reduced the mobility of the macromolecular chains of the PC melt. As can be seen on the figure, the green pigment mobility of the macromolecular chains almost linearly declines. The trend is not the same for blue and red pigment. The mobility plunges at the beginning and then there is a slight grow with increasing concentration of the pigment

\section{Conclusion}

In conclusion, it is clear that pigments have a certain effect on PC shrinkage. However, the shrinkage of the test sample differs with the use of each pigment. This plays a role especially in the production of the same components, which will diverge only in the color. However, this different shrikage may be affected by changing the technological parameters during the injection moulding process. Because of that, it is important to use the constant injection moulding parameters for the possibility of the comparison. Every pigment influences the shrinkage of the material differently. For this reason, it is desirable to use the same polymeric matrix for all pigments. Nowadays, the plastics industry offers a considerable amount of different pigments and thus it is relatively easy to choose those pigments which affect the shrinkage similarly for all desired colours.

The most optimal interval for the shrinkage is in the range from $2 \%$ to $4 \%$ of the pigment concentration. It has been shown that pigments have an effect on PC melt MFI. It is possible to deduce that pigments affect the flow of the base material, which can be seen on the flow curve. Rheological behaviour of the polymer melt can be judged from the flow curve on throughout the injection moulding process. This area should be further examined.

\section{Acknowledgement}

This paper is supported by the internal grant of $T B U$ in Zlin No. IGA/FT/2019/002 funded from the resources of specific university research and by the Ministry of Education, Youth and Sports of the Czech Republic within the National Sustainability

Programme project No. LO1303 (MSMT-7778/2014) and also by the European Regional Development Fund under the project CEBIA-Tech No. CZ.1.05/2.1.00/19.0376 contribution. We are looking forward to seeing you at the Conference.

\section{References}

[1] JANOSTIK, V., STANEK, M., SENKERIK. V., JELINKOVA, K. (2017) Effect of pigment concentration on mechanical properties and on color stability of polycarbonate. WSEAS Transactions on Environment and Development. vol. 13, p. 487494

[2] JANOSTIK, V., STANEK, M., SENKERIK. V., MANAS, D., MANAS, M. (2016).The Influence of runner system on production of injection molds, MATEC Web of Conferences 20th International Conference on Circuits, Systems, Communications and Computers . vol. 76

[3] .STANEK, M., MANAS, D., MANAS, M., PATA, V., SANDA, S., SENKERIK. V., SKROBAK, A. (2011). How the Filler Influence the Fluidity of Polymer, Chemicke listy.

[4] STANEK, M., MANAS, D., MANAS, M.,SUBA, O. (2011). Optimization of injection molding process, Intl. J. of Math. and Computers in Simul., Vol.5, No.5,

[5] JAVORIK, J., STANEK, M. (2011), The shape optimization of the pneumatic valve diaphragms, Intl. J. of Math. and Computers in Simul., Vol.5, No.4,

[6] STANEK, M., MANAS, D., MANAS, M, JAVORIK, J. (2011) Simulation of injection molding process by cadmould rubber, Intl. J. of Math. and Computers in Simul., Vol.5, No.5,

[7] DOBRANSKY, J. (2013), et al. Comparison of Cooling Variants by Simulation Software. Advanced Materials Research. Vol. 801. pp. 75-80. ISSN 1022-6680.

[8] OVSIK, M., STANEK, M., HYLOVA, L., MANAS, M., STOKLASEK, P (2019) The thermal energy influence on the surface layer of construction steels during laser beam cutting, Manufacturing Technology, 19 (1), pp. 123-128.

[9] BILEK, O., PATA, V., KUBISOVA, M., REZNICEK, M., (2018) Mathematical methods of surface roughness evaluation of areas with a distinctive inclination, Manufacturing Technology, 18 (3), pp. 363-368. 